\title{
Hylomysobia gen. n. (Acari: Myobiidae), a new genus of mites parasitic on gymnures of the genus Hylomys (Eulipotyphla: Erinaceidae)
}

\author{
Andre V. Bochkov ${ }^{1,2}$ and Barry M. OConnor ${ }^{2}$ \\ ${ }^{1}$ Zoological Institute, Russian Academy of Sciences, Universitetskaya embankment 1, St. Petersburg 199034, Russia; \\ ${ }^{2}$ Museum of Zoology, University of Michigan, 1109 Geddes Avenue, Ann Arbor, Michigan 48109, USA
}

Key words: mites, Myobiidae, parasites, Hylomysobia, gymnures, Hylomys, systematics

\begin{abstract}
A new genus of Myobiidae, Hylomysobia gen. n. with two new species, H. mikhailzaitzevi sp. n. (type species) and $H$. chinensis sp. n., is described from gymnures of the genus Hylomys Müller (Eulipotyphla: Erinaceidae). The two species parasitize Hylomys suillus Müller from Cambodia and Vietnam, and Hylomys sinensis (Trouessart) from China, respectively. These species represent the first records of myobiid mites from species in the family Erinaceidae. The new genus differs from the closely related Eutalpacarus Jameson, 1949 by the following features: in both sexes, coxae I have a triangular process, setae ve are about three times wider than sce and $c 2$, and coxae II bear two pairs of setae; in females, setae sci are lanceolate, setae agl and ag3 are absent, and the vulvar lobes are weakly developed; in males, setae $e 2$ are absent, and setae $c 1, d 1, d 2$ and $e 1$ are situated on the genital shield. The life cycle of Hylomysobia spp. includes egg, larva, protonymph, deutonymph, and adults, male and female. In contrast to the most other myobiid genera possessing the tritonymphal stage, the deutonymphs of Hylomysobia moult directly to adults, and the tritonymphs are absent. Based on the restricted distribution of Hylomysobia species on hosts of this family (only on species of the genus Hylomys) and close morphological similarities to myobiids from Soricidae and Talpidae, it is suggested that the ancestor of this genus secondarily colonized the ancestor of Hylomys from moles or shrews.
\end{abstract}

Mites of the family Myobiidae Mégnin, 1778 (Acari: Prostigmata) are permanent highly specialized parasites of small marsupial and placental mammals (Dusbábek 1969, Fain 1994). To date, 15 myobiid genera are known from "insectivores" of the families Soricidae, Talpidae (Eulipotyphla) and Tenrecidae (Afrotheria) (Fain and Lukoschus 1976, Uchikawa 1986, Bochkov 1997a). During a survey of atopomelid mites (Acari: Atopomelidae) parasitizing gymnures (Eulipotyphla: Erinaceidae) (Bochkov et al. 2005), we have collected myobiids from several museum specimens belonging to two species of the genus Hylomys Müller, H. sinensis (Trouessart) and $H$. suillus Müller. Each host species harboured a new species that differed from all described myobiid genera. In the present paper we describe these taxa based on all stages of their life cycle.

\section{MATERIALS AND METHODS}

The specimens examined in this study were collected by AVB from dried or fluid-preserved host specimens in the Field Museum of Natural History, Chicago, USA. The collection locality information is taken from the original host labels. Some early 20th century Chinese localities could not be located in modern references due to original inaccuracies or changes in transliteration. These are reproduced as on the original host specimen labels. Parasites removed were cleared in lactophenol and mounted in Hoyer's medium. Drawings were made with a Zeiss microscope with phase contrast optics and a camera lucida. In the descriptions below, idiosomal chaetotaxy follows Grandjean (1939) as interpreted by Kethley (1982) rather than the earlier nomenclature used for Myobiidae (Fain 1973). In both sexes of the Myobiidae, the prodorsal setae are strongly displaced posteriorly because of the dorso-apical position of legs I, nevertheless, they are still easy recognizable. According to the nomenclature of Fain (1973), the setation of the female hysteronotum includes two series of hysteronotal setae, lateral and median, each with five pairs of setae ( $l 1-l 5$ and $d 1-d 5$ ), with setae $l 2$ medially displaced. We regard each pair of the median and lateral setae as corresponding to the respective hysterosomal segments, C, D, E, F, and H (see Fig. 1). In Myobiidae, the homologies between the dorsal idiosomal setae of males and females are clearly established only for the propodosomal setae ( $e l, v i, v e$, $s c i$ and sce) and the hysterosomal setae $c 2$ because of the strong sexual dimorphism. The genital shield of myobiid males is displaced dorsally, and in some species, it is situated on the propodosoma. Therefore, in the process of this displacement, most of the dorsal hysterosomal setae are also displaced or lost. An attempt to elucidate the homologies of these setae was recently proposed by Fain and Bochkov (2002). According to a new interpretation of their data, the aggenital setae are absent in myobiid males and the genital shield ancestrally bears three pairs of pseudanal setae, two pairs of genital setae, and in addition, incorporates one to four pairs of hysteronotal setae, probably, $c 1, d 1$ and $d 2, e l$. The leg chaetotaxy follows Grandjean (1944). All measurements are given in micrometres $(\mu \mathrm{m})$. Names of hosts follow Jenkins and Robinson (2002). The supraspecific system of "insecti- 
vores" follows more recent works that support the polyphyly of the traditional mammalian order Insectivora (or Lipotyphla) and recognize two orders, Eulipotyphla (including Erinaceidae, Solenodontidae, Soricidae and Talpidae) and Afrosoricida (including Chrysochloridae and Tenrecidae) (Stanhope et al. 1998). Specimen depositories and reference numbers are cited using the following abbreviations: BMOC - B.M. OConnor reference number; FMNH - Field Museum of Natural History, Chicago, USA; IPCR - Institute of Parasitology, Academy of Sciences of the Czech Republic, České Budějovice, Czech Republic; UMMZ - University of Michigan Museum of Zoology, Ann Arbor, USA; ZISP - Zoological Institute, Russian Academy of Sciences, Saint-Petersburg, Russia.

\section{RESULTS}

Family: M y o bi i d a e Mégnin, 1778

Subfamily: Prot o m y o bi i n a e Bochkov, 1997

Tribe: Pr ot o m y o b i i n i Bochkov, 1997

\section{Hylomysobia gen.n.}

Generic diagnosis. Adults: Gnathosoma triangular in shape, distinctly shorter than legs I, with 3 pairs of filiform setae, ao1, ao2, $n$, one pair of dorsal-cheliceral setae $c h$ represented by alveoli, and pair of short ventral processes. Idiosoma elongated. Setae vi microsetae, ve about 3 times wider than sce and $c 2$. Legs I bilaterally

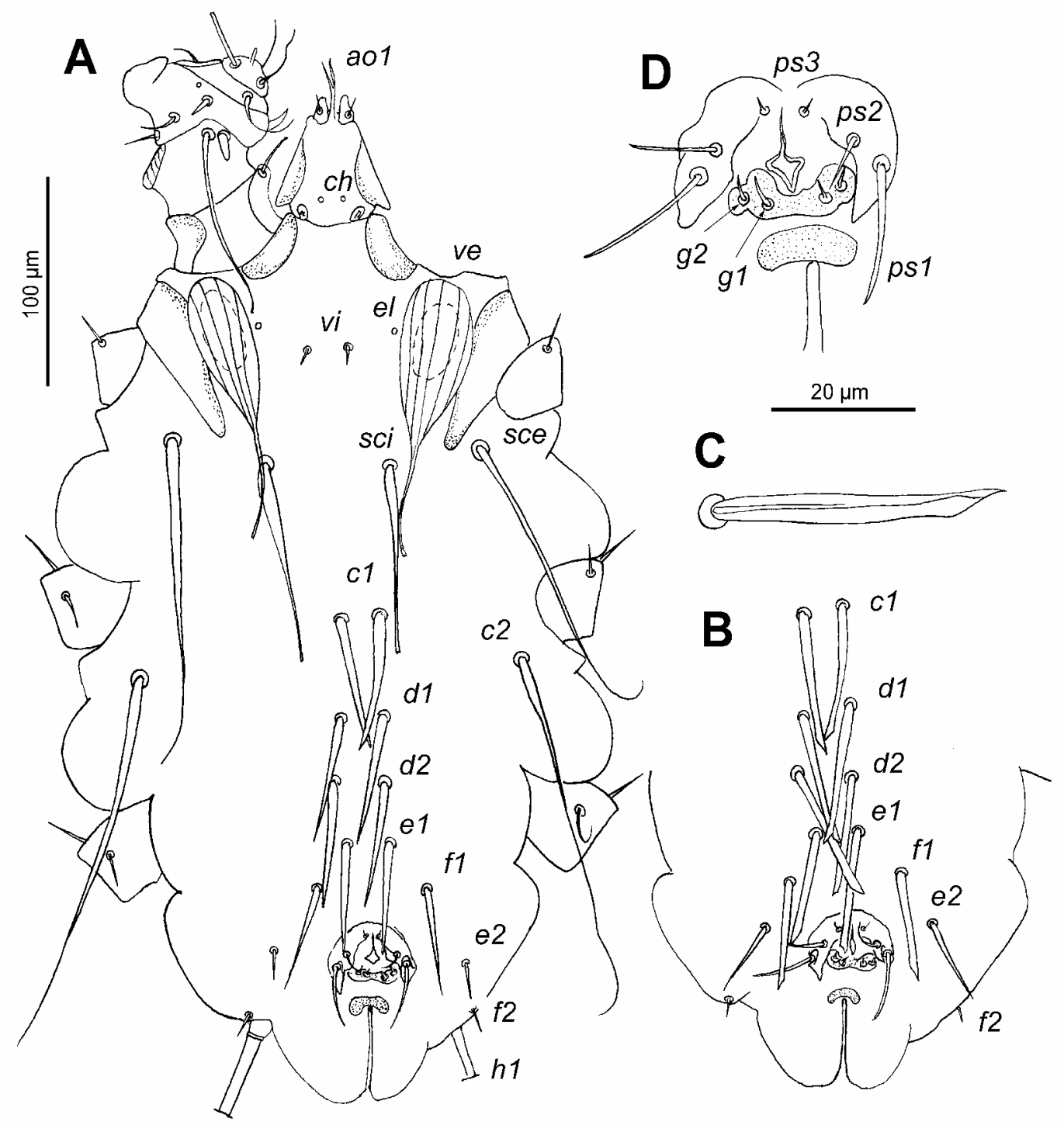

Fig. 1. Females of Hylomysobia mikhailzaitzevi sp.n. (A) and H. chinensis sp.n. (B-D). A - body, dorsal view; B - hysterosoma, dorsal view; $\mathbf{C}$ - seta $d 2 ; \mathbf{D}$ - vulva. 


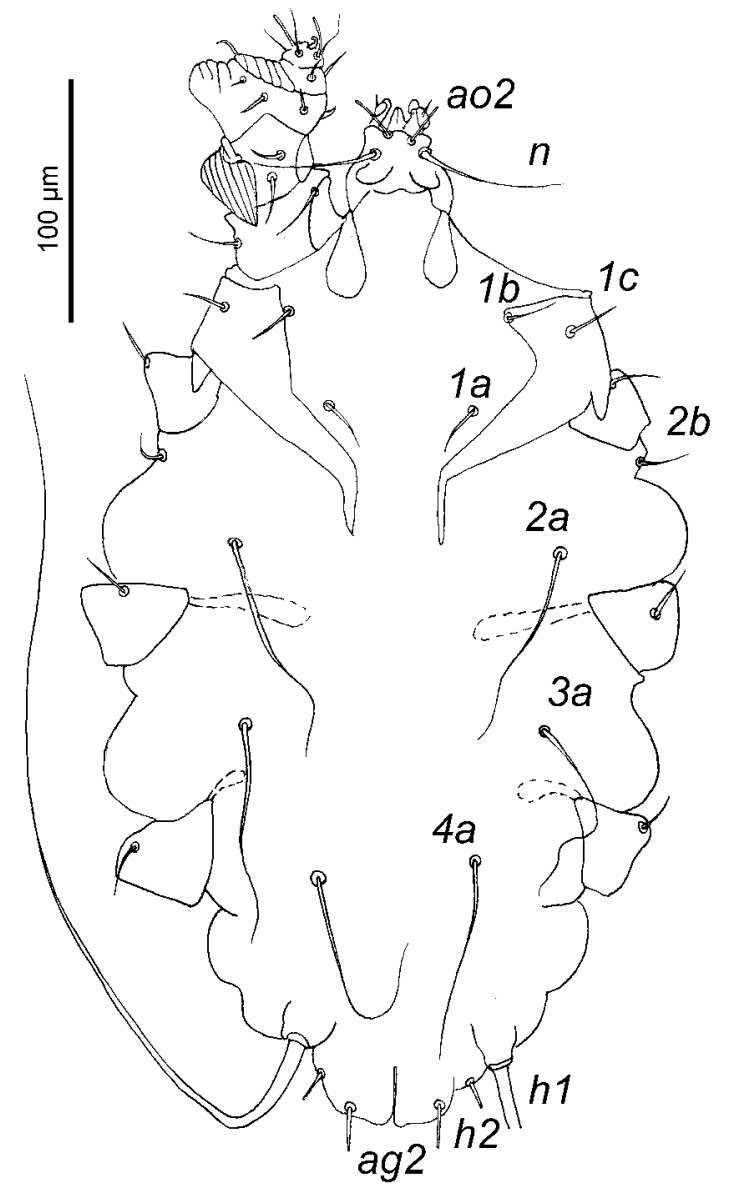

Fig. 2. Hylomysobia mikhailzaitzevi sp. n., female body, ventral view.

symmetrical, with tibia and tarsus partially fused. Setae $l$ ' and $l l$ " of femur I finger-like, seta $l$ "striate foliate closely situated to seta $l l$ ". Clasping organ of genu I with anteriorly directed spine-like seta $d l$. Tibiae I covered ventrally with striate seta. Tarsus I strongly reduced. Coxae I with pair of triangular processes directed posteriorly and 3 pairs of thin filiform setae. Tibiae II with short ventral process. Leg I-IV setation (solenidia in brackets): coxae 3-2-1-1, trochanters 3-2-3-3, femora 6-5-2-2, genua 8(1)-6(1)-5-5, tibiae 6-6-6-6, tarsi 8(1)7(1)-6-6. Claw formula 2-2-2-2 (claws of legs III-IV unequal).

Female: Idiosomal setation: $e l, v i, v e, s c i, s c e, c 1, c 2$, $d 1, e 1, e 2, f 1, f 2, h 1, h 2,1 a-4 a, g 1, g 2, p s 1-p s 3, a g 2$. Setae $a g 1$ and ag3 absent. Vulva with pair of weakly developed membranous lobes. Setae ps 3 microsetae, setae $p s 2$ and $p s 1$ well developed, setiform. Oviporous aperture distinctly separated from vulva.

Male: Idiosomal setation: el, vi, ve, sci, sce, c2, fl, $h 1,1 a-4 a$. Setae $s c i$ microsetae. Genital shield rounded, bearing 9 pairs of setae, probably, $g 1, g 2, p s 1-p s 3, c 1$, $d 1, d 2$, and $e 1$. Aedeagus loop-shaped.

Larva: Idiosomal setae $e l, v e, s c i, s c e, c 1, c 2, d 1, d 2$, $e l, f l, h l$, and $1 a$ present. Setae $v i$ and pseudanal setae (ps) absent. Setae $d 1$ situated distinctly anterior to setae $d 2$. Setae ve and sci narrowly lanceolate, $h l$ whip-like, all other setae rod-like. Lengths of setae: ve 15-20, sci 45-50, sce and $c 210-12, c 1, d 1, d 2, e 1, f 1$, and $1 a$ 5-8, h1 210-230. Legs I-III present. Legs I bilaterally symmetrical. Tibiae II with short ventral process. Leg I-III setation (solenidia in brackets): trochanters 0-0-0, femora-genua 3(1)-2(1)-0, tibiae 5-5-4, tarsi ?6(?)-7(1)6. Claw formula 0-2-1 (claws of legs II unequal).

Protonymph: Setae $c 1, d 1$, and $d 2$ lost; setae $e 2$ added. Scale-like setae $1 b$ and very short rod-like setae $2 a$ and $3 a$ added ventrally. Legs IV added. Leg I-IV setation (solenidia in brackets): trochanters $0-0-0-0$, femora-genua 3(1)-4(1)-2-0, tibiae 6-5-4-4, tarsi ?6(?)7(1)-6-6. Claw formula 0-2-1-1 (claws of legs II unequal).

Deutonymph: Setae $f 2$ and $4 a$ added. Leg I-IV setation (solenidia in brackets): trochanters 0-1-1-0, femoragenua 5(1)-4(1)-2-2, tibiae 6-5-4-4, tarsi ?6(?)-7-6-6. Claw formula 0-2-1-1 (claws of legs II unequal).

Type species: Hylomysobia mikhailzaitzevi sp. n.

Host order, family and subfamily: Eulipotyphla, Erinaceidae, Galericinae.

Other species included: $H$. chinensis sp. $\mathrm{n}$.

E t y m o lo g y: The generic name is derived from the stem of the generic name of the host (Hylomys).

Differential diagnosis. This new genus belongs to the Amorphacarus generic complex that includes the following seven genera: Amorphacarus Ewing, 1938, Blarinobia Jameson, 1955, Chimarrogalobia Uchikawa, 1986, Crocidurobia Jameson, 1970, Eutalpacarus Jameson, 1949, Gymnomyobia Fain et Lukoschus, 1976, and Placomyobia Jameson, 1970 (Bochkov 1997a). This group is characterized by the following combination of characters: tarsi I are strongly reduced, tibiae I are covered ventrally with a flattened, striate seta, seta $l 1$ " of femora I is finger-like, and the idiosoma is elongated. Among these genera, Hylomysobia is most closely related to Eutalpacarus. In both of these genera, legs I are bilaterally symmetrical, tarsi I bear claws, tarsi III and IV bear two unequal claws each, and setae $v i$ are microsetae. The new genus differs from Eutalpacarus by several characters. In both sexes of Hylomysobia, coxae I bear triangular process, setae ve are about three times wider than sce and $c 2$, coxae II bear two pairs of setae; in females, setae $s c i$ are lanceolate, 68-75 long, setae ag1 and ag3 are absent, the vulvar lobes are weakly developed; in males, setae $e 2$ are absent, setae $c 1, d 1$, $d 2$, and $e 1$ are situated on the genital shield and are microsetae. In both sexes of Eutalpacarus, coxae I lack processes, setae ve and sce are subequal in width, coxae II bear four pairs of setae; in females, setae sci are microsetae, setae $a g 1$ and $a g 3$ are present, the vulvar lobes are distinctly developed; in males, setae $e 2$ are present, setae $c 1, d 1, d 2$ and $e 1$ are situated off the genital shield and longer than $f 1$. 
Bochkov, OConnor: Mites of the genus Hylomysobia gen. n.

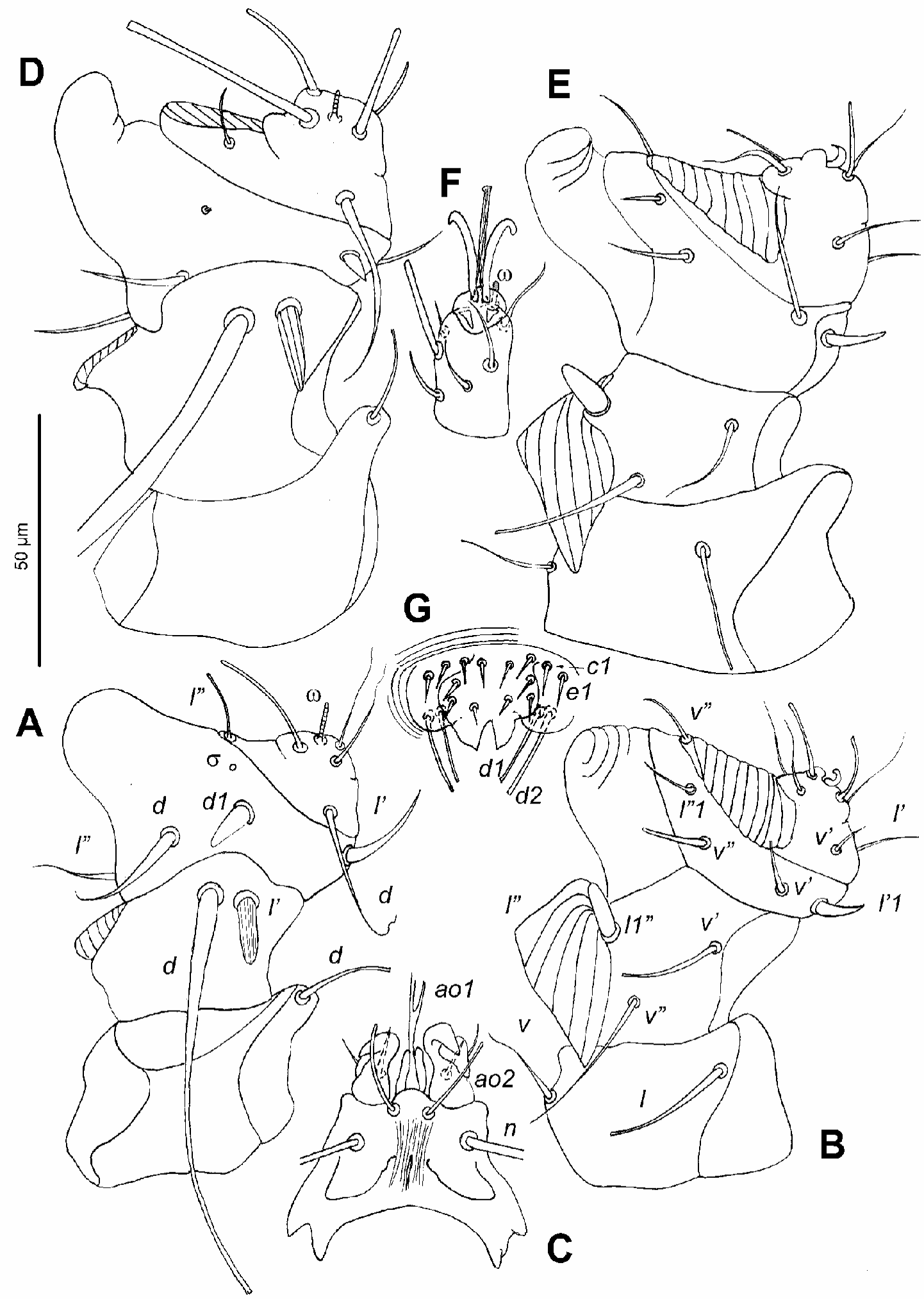

Fig. 3. Hylomysobia mikhailzaitzevi sp. n., female (A-C) and male (D-G). A - leg I, dorsal view; B - same, ventral view; C gnathosoma, ventral view; D - leg I, dorsal view; E - same, ventral view; F - tarsus II, ventral view; G - genital shield. 


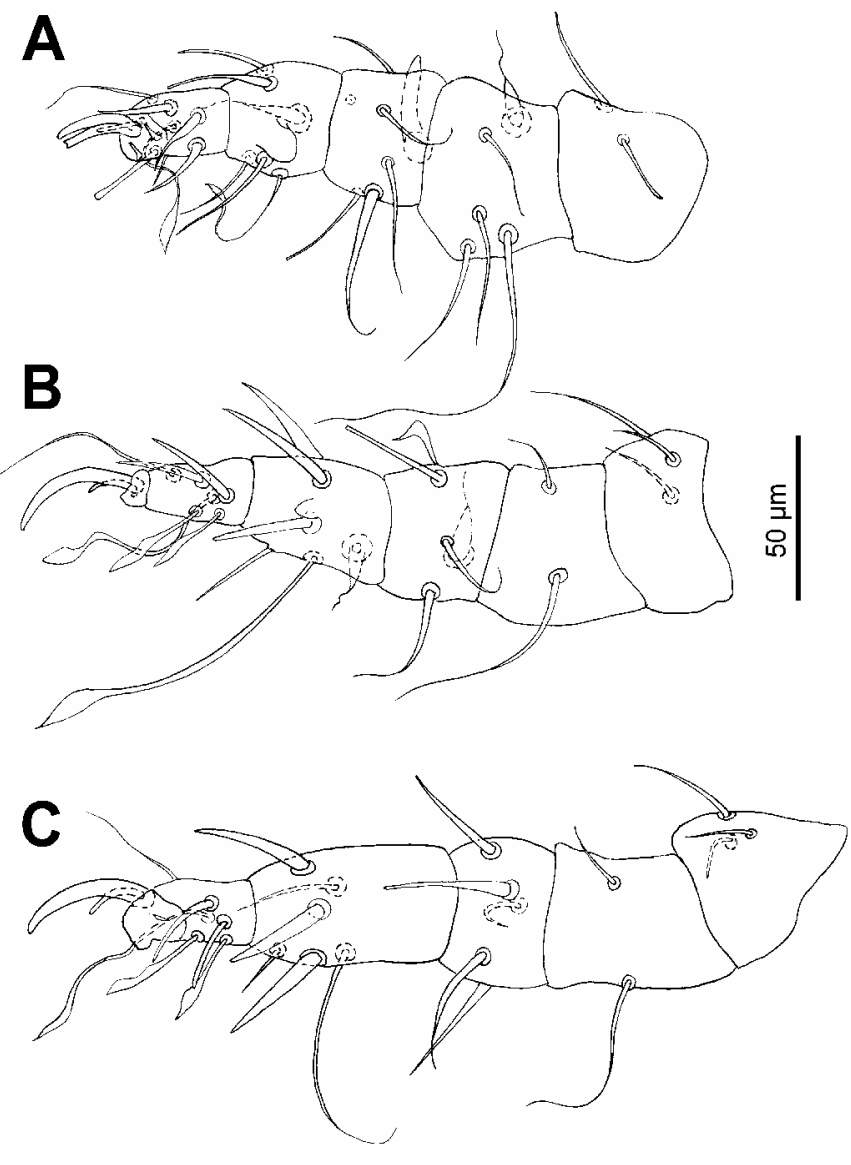

Fig. 4. Hylomysobia mikhailzaitzevi sp. n., female legs II-IV (A-C) in ventral view, respectively.

\section{Hylomysobia mikhailzaitzevi sp. n. Figs. 1A, 2-7}

Description. Female (holotype, Figs. 1A, 2, 3A-C, 4): Body, including gnathosoma, $410(390-415$ in 3 paratypes) long, 215 (210-220) wide. Setae ve widely lanceolate, about 22 wide, sci, sce, $c 1, c 2, d 1, d 2, e 1$ and f1 narrowly lanceolate, with pointed apices (Fig. 1A), setae $e 2, f 2$ and $h 2$ rod-like. Distances $d 1-d 1$ and $d 2-d 2$ subequal, about 13, distance el-el about 15, distances $f 1-f 1$ and $e 2-e 2$ about 40 and 70, respectively. Length of setae: vi microsetae, ve 95 (90-95), sci 55 (50-57), sce and $c 1$ 135-140,c2, d1, d2, el and $f 1-$ all about 40,e2, $f 2, h 2$ and ag2 10-13, h1 355 (350-370), la about 15, $2 a, 3 a$ and $4 a$ 60-70, ps 2 about 12, ps 1 about 25 .

Male (2 paratypes, Figs. 3D-G, 5): Body, including gnathosoma, 290-300 long, 275-280 wide. Setae vi and sci situated distinctly behind levels of ve and sce bases, respectively. Distance sce-sce 2 times longer than scisci. Genital shield as in Fig. 3G, situated slightly anterior to level of seta $c 2$ bases. Aedeagus 100-105 long. Length of setae: ve 70-75, sce 120-125, c2 120-130, f1 8-12, hl 320-330, $1 a$ 14-15, $2 a$ and $3 a$ 70-75, and $4 a$ $8-9$.
Larva (1 paratype, Fig. 6A-D): Distances $d 1-d 1$ and $d 2-d 2$ subequal. Distance $f 1-f 1$ about 1.5 shorter than e1-e1. Lengths of setae: ve 15, sci 50, sce and c2 9-10, $c 1, d 1, d 2, e 1, f 1$ and $1 a$ 5-7, h1 210.

Protonymph (2 paratypes, Fig. 6E-H): Setae el widely separated from each other, distance $e 1-e 1$ about 2 times longer than $f 1-f 1$. Length of setae: ve 25-30, sci 60-70, sce 15-20, c2 10-15, el-2, fl, $2 a$ and $3 a$ 7-8, h1 230-245.

Deutonymph (6 paratypes, Fig. 7): Length of setae: ve 30-35, sci 55-57, sce 12-14, c2 10-11, e1-2, f1-2, 2 a and $3 a$ 7-8, h1 220-240.

T y p e host: Hylomys suillus Müller (FMNH 168563).

$\mathrm{M}$ i c r o h a b i t a t: Posterior dorsal body.

T y p e 1 o c a 1 i t y : Province of Kampot, Bokor, $10^{\circ} 37^{\prime} \mathrm{N}$, 104 $03^{\prime}$ 'E (Cambodia).

Date of collection of holotype: 25 July 2000, R.H. Pine coll.

Deposition of type material: Holotype female (BMOC 04-0331-105 1), 1 female, 2 male, 4 deutonymph, 2 protonymph, and 1 larva paratypes (BMOC 04-0331-105 2-12) in FMNH; 1 female and 2 deutonymph paratypes (BMOC 04-0331-105 13-15) in UMMZ; 1 female paratype (BMOC 04-0331-105 16) in IPCR (Coll. No. 2007).

A d d it i o n a $1 \mathrm{~m}$ a teria $1: 2$ females, 3 pharate males in deutonymphal exuvium, 11 deutonymphs, 1 pharate deutonymph in protonymphal exuvium, 2 protonymphs, 1 larva (BMOC 04-0331-113 1-20) ex H. suillus (FMNH 146635), province of Lam Dong, Langbian peak, $12^{\circ} 03^{\prime} \mathrm{N}, 108^{\circ} 27^{\prime} \mathrm{E}$ (Vietnam), 21 February 1937, W.H. Osgood coll. (FMNH, UMMZ, ZISP).

E t y m o 1 o g y : This species is named in memory of Dr. Mikhail Zaitzev (ZISP), the prominent specialist in the systematics of lipotyphlans.

\section{Hylomysobia chinensis sp. n.}

Fig. 1B-D

Description. Female (holotype, Fig. 1B-D): Body, including gnathosoma, 390 (390-420 in 3 specimens) long, 200 (190-200) wide. Setae ve widely lanceolate, 20-22 wide, sci, sce, $c 1, c 2, d 1, d 2, e 1-2$ and $f 1$ narrow lanceolate, with sword-like apices (Fig. 1C), setae $f 2$ and $h 2$ rod-like. Distances $d 1-d 1$ and $d 2-d 2$ subequal, about 10, distance el-el about 15, distances $f 1-f 1$ and $e 2-e 2$ about 35 and 55, respectively. Length of setae: $v i$ microsetae, ve 100 (95-110), sci 70 (68-75), sce and $c 1$ 130-140, c1, d1, d2, e1- all about 45, f1 39 (38-40), e2 35 (33-37), f2, h2 and ag2 10-15, h1 355 (350-370), la about 18, $2 a, 3 a$ and $4 a$ 60-70, ps 2 about 13,ps 1 about 25.

Male (3 paratypes): Body, including gnathosoma, 270-280 long, 160-170 wide. Setae vi and sci situated distinctly posterior to levels of ve and sce bases, respectively. Distance sce-sce 2 times longer than sci-sci. Genital shield as in previous species, situated slightly anterior to level of $c 2$ bases. Aedeagus 110-115 long. Length of setae: ve 80-85, sce 115-120, c2 120-125, 


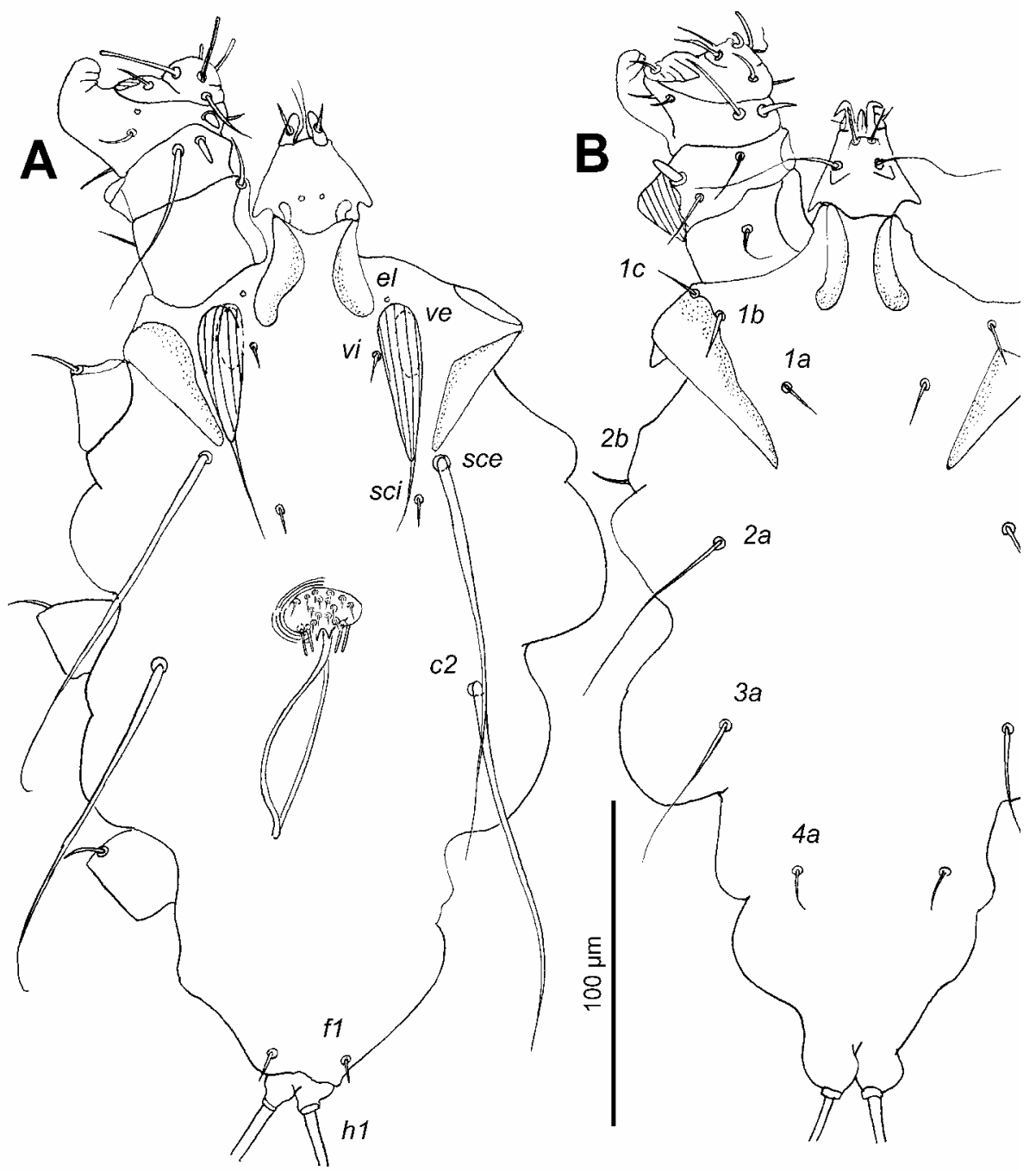

Fig. 5. Hylomysobia mikhailzaitzevi sp. n., male. A - dorsal view; B - ventral view.

fl 10-12, h1 350-360, $1 a$ 15-17, $2 a$ and $3 a$ about 70, $4 a 9-10$.

Larva (1 paratype): Distances $d 1-d 1$ and $d 2-d 2$ subequal. Distance $f 1-f 1$ about 1.5 shorter than $e 1-e 1$. Setae ve and sci narrow lanceolate, $h l$ whip-like, all other setae rod-like. Length of setae: ve 23, sci 87, sce 12, c1, $d 1, d 2, f 1$ and $1 a$ about $9, c 2$ and $e 1$ about 13, h1 195

Deutonymph (2 paratypes): Length of setae: ve 4042, sci 70-75, sce 23-25, c2 20-22, e1-2 and f1-2 1314, $2 a$ and $3 a$ 6-7, h1 230-250.

T y p e hos t: Hylomys sinensis (Trouessart) (FMNH 37017

- holotype and deutonymph paratype; FMNH 37021 - 3 male, 1 deutonymph and 1 larva paratypes).

M i c r o h a b it a t: Posterior dorsal body.

Ty pe 1 o c a lity: Province Sichuan, Dan Shi Go (China).

Dates of collection of type series: 10 November 1931, F.T. Smith coll. (holotype and deutonymph paratype); 3 December 1931, F.T. Smith coll. (3 male, 1 deutonymph and 1 larva paratypes).
Deposition of type materia 1: Holotype female (BMOC 04-0331-0851), 1 deutonymph paratype (BMOC 04-0331-085 2), 1 male, 1 deutonymph and 1 larva paratypes (BMOC 04-0331-087 1-3) in FMNH; 1 pharate male paratype (BMOC 04-0331-087 4) in UMMZ; 1 male paratype (BMOC 04-0331-087 5) in IPCR (Coll. No. 2008).

A d d it i o n a 1 mate ri a 1: 1 female (BMOC 04-0331089) ex H. sinensis (FMNH 37023), province of Shandong, Mouping, $37^{\circ} 23^{\prime} \mathrm{N}, 21^{\circ} 35^{\prime} \mathrm{E}$ (China), 18 December 1931, F.T. Smith coll. (UMMZ); 2 females (BMOC 04-0331091) ex H. sinensis (FMNH 36667), province of Sichuan, Tao Cho Fu (China), 14 March 1932, F.T. Smith coll. (FMNH, UMMZ).

E t y m o lo g y : The species name is derived from the name of the country of the type locality and is an adjective.

Differential diagnosis. The males of $H$. chinensis and $H$. mikhailzaitzevi are almost indistinguishable from each other, whereas the females and deutonymphs are clearly separated by the following characters. In females 


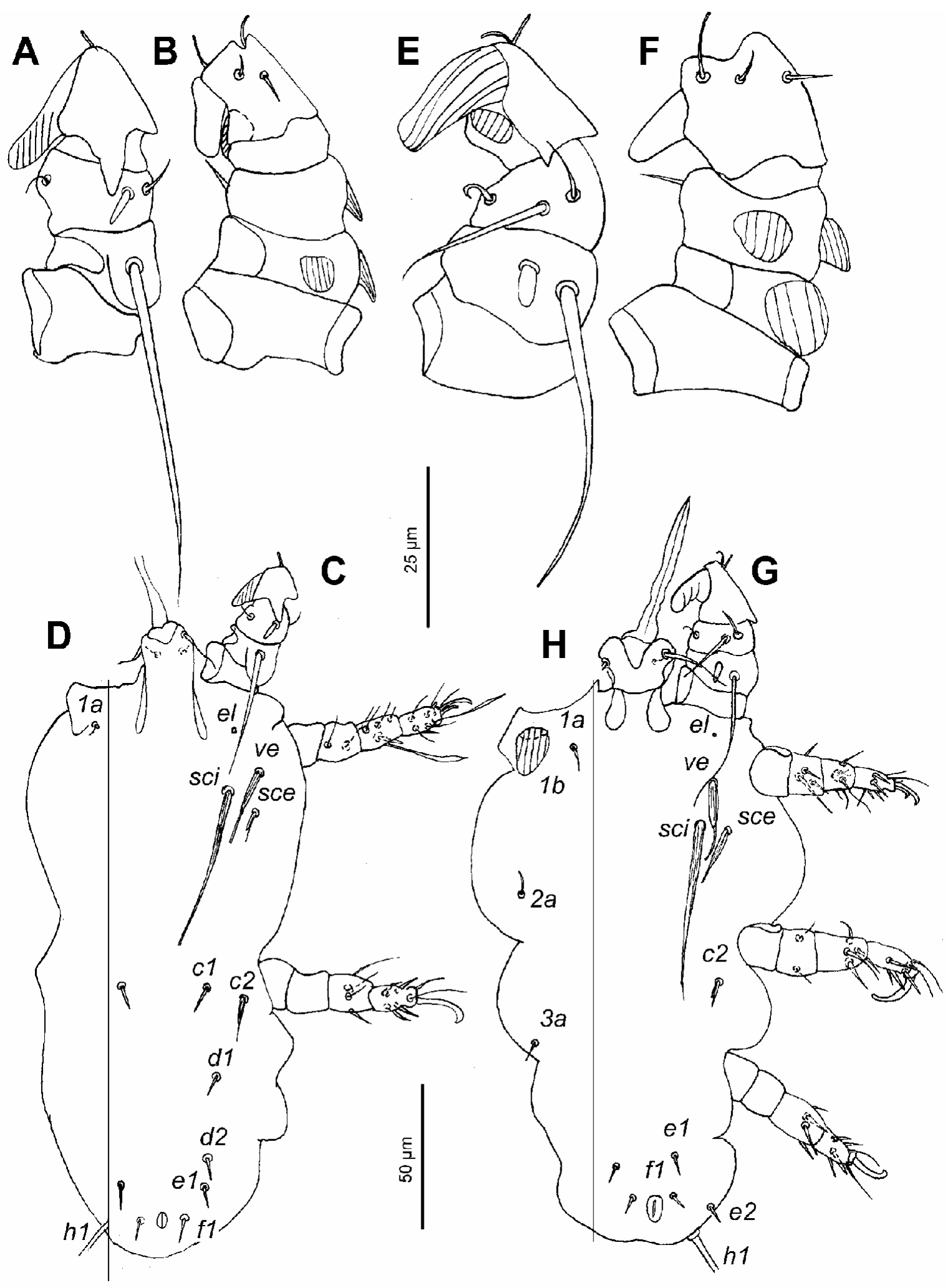

Fig. 6. Hylomysobia mikhailzaitzevi sp. n., larva (A-D) and protonymph (E-H). A - leg I, dorsal view; B - same, ventral view; C - body, dorsal view; D - same, ventral view; $\mathbf{E}$ - leg I, dorsal view; F - same, ventral view; $\mathbf{G}$ - body, dorsal view; H - same, ventral view. 

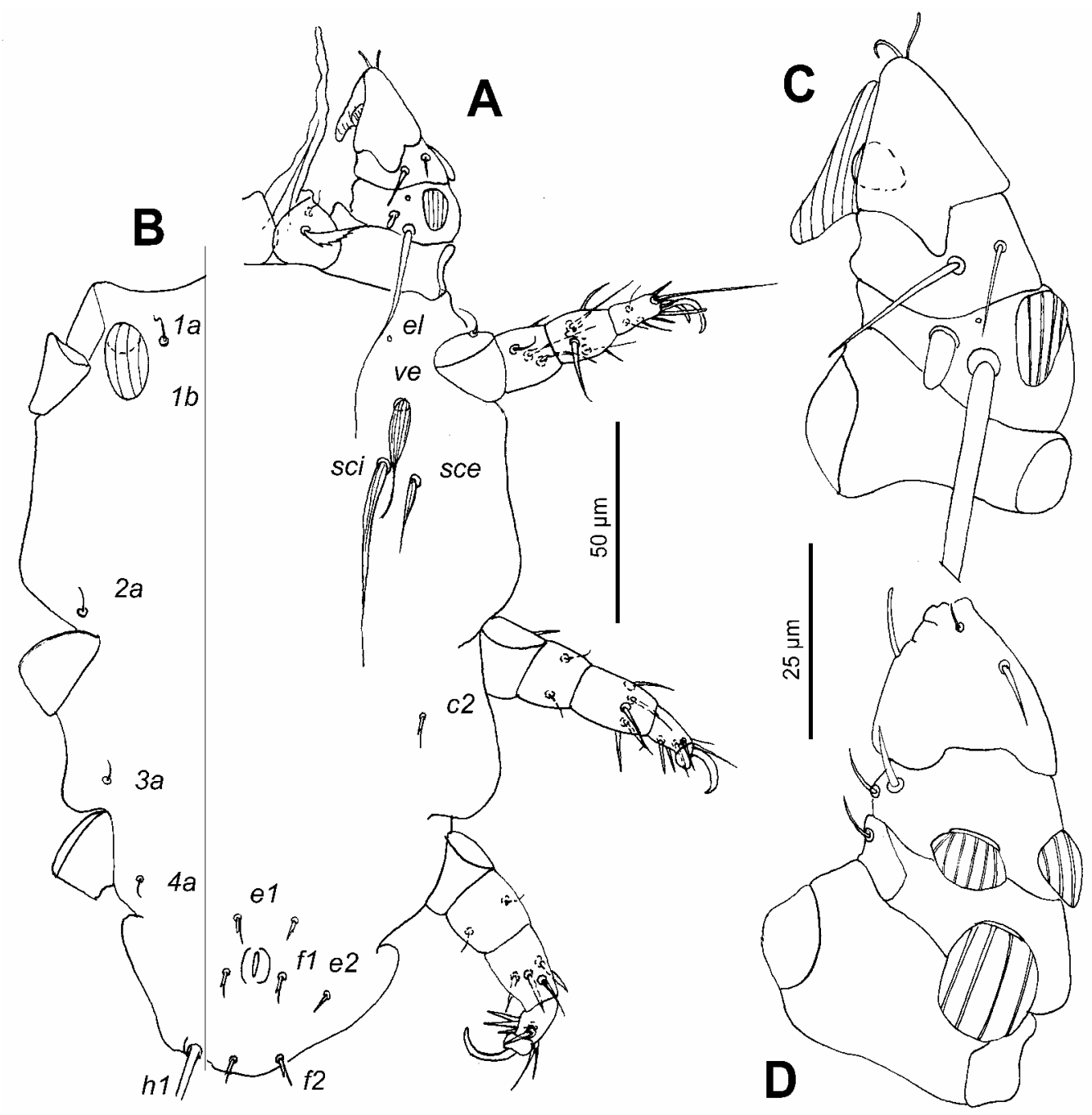

Fig. 7. Hylomysobia mikhailzaitzevi sp. n., deutonymph. A - body, dorsal view; $\mathbf{B}$ - same, ventral view; $\mathbf{C}$ - leg I, dorsal view; D - same, ventral view.

of $H$. chinensis, the apices of hysteronotal setae $c l, d l$, $d 2$ and $f 1$ are sword-like, setae $e 2$ are distinctly lanceolate, 33-37 long; in deutonymphs, setae $c 2$ are 20-22 long. In females of $H$. mikhailzaitzevi the apices of hysteronotal setae $c 1, d 1, d 2$ and $f 1$ are sharply pointed, setae $e 2$ are rod-like, 10-13 long; in deutonymphs, setae c2 are 10-12 long.

\section{DISCUSSION}

Life cycle. The life cycle is known for at least one species in the majority of myobiid genera and normally consists of egg, larva, three nymphal stages (proto-, deuto-, female and male tritonymphs), and adults, female and male (Bochkov 1997b). In the case of Hylomysobia, however, only two nymphal stages (nymphs I and II) were collected. Among them, we observed both pharate males within nymphs II and nymphs II within nymph I specimens. The tritonymphs of most myobiids have three pairs of setae $(1 a-3 a)$ on coxae I, and their leg setation is usually almost the same as in the respective adults (Bochkov 1997b). The leg and idiosomal setation in nymphs I and II of Hylomysobia spp. completely corresponds to those of protonymphs and deutonymphs of the other myobiid genera associated with "insectivores" and bats (Uchikawa 1986, Lukoschus and Driessen 1971, Dusbábek 1973). In Myobiidae, the suppression of the tritonymph, with the deutonymph moulting to the adult is known in Ewingana Radford, 1952 (Bochkov 1997b). Therefore, we believe that the missing nymphal stage in Hylomysobia is the tritonymph. The ontogenetic appearance of certain setae in Hylomysobia is delayed and the setae are lost, patterns which are very characteristic for mites of Protomyobiinae (Bochkov 1997b). The larva of Hylomysobia retains almost the maximum set of idiosomal setae for this 
stage: el, ve, sci, sce, $c 1, c 2, d 1, d 2, e 1, f 1, h 1$ and $1 a$, excluding setae $v i$ and $p s 1-2$, which are absent in almost all species of the subfamily. In the subsequent immature instars, most of the median hysteronotal setae disappear and appear again only in adults.

Host-parasite relationships. It is unclear whether these myobiids are ancestrally associated with gymnures or their parasitism of these hosts is a result of secondary switching. Among hosts of the family Erinaceidae, myobiids parasitize only species of Hylomys. This genus includes five species, and myobiids are known from two of them (present paper). The three other species, Hylomys hainanensis (Shaw et Wong), H. parvus Robinson et Kloss, and $H$. megalotis Jenkins et Robinson, are known from few specimens and have not yet been examined for ectoparasites. Two other genera of the subfamily Galericinae, Podogymnura Mearns with two species endemic to the Philippines, and Echinosorex Blainville with one species, E. gymnura (Raffles), were also examined for the presence of the Myobiidae. We examined 64 specimens of Podogymnura truei Mearns from Mindanao Island without finding myobiids. The second species of Podogymnura, P. aureospinula
Heaney et Morgan, occurs only on Dinagat Island and has not been examined yet. We have examined 14 specimens of E. gymnura without recovering myobiids. We have also examined several hundred specimens of various species of hedgehogs without collecting Myobiidae and conclude that this family is probably completely absent on species in the subfamily Erinaceinae. Species of Hylomysobia are morphologically similar to mites parasitizing moles (Eutalpacarus) and shrews (Amorphacarus, Crocidurobia, Placomyobia) (see generic diagnosis). On the basis of the host distributions and morphological similarities, it seems likely that the ancestor of Hylomysobia switched secondarily onto an ancestral species of Hylomys from another insectivore, either a mole or shrew.

Acknowledgements. We thank Dr. L. Heaney (FMNH), who provided access to the host specimens examined in this study, and Dr. S. Mironov (ZISP) for critical reviewing the manuscript. This research was supported by a grant from the Russian Foundation for Basic Research (RFFI N 03-04-49072) to AVB and the U.S. National Science Foundation DEB0118766 (PEET) to BMOC.

\section{REFERENCES}

BOCHKOV A.V. 1997a: Mites of the family Myobiidae (Acariformes: Prostigmata) parasitic on Lipotyphla (Mammalia) in the fauna of the former USSR. Acarina 5: 45-62.

BOCHKOV A.V. 1997b: A new classification of the myobiid mites (Acari, Acariformes). Entomol. Rev. 76: 938-951.

BOCHKOV A.V., KLIMOV P.B., OCONNOR B.M. 2005: Fur-mites of the genus Atopomelus Trouessart, 1918 (Acari: Atopomelidae), life cycle, phylogeny and hostparasite associations. Acarologia 45: 209-242.

DUSBÁBEK F. 1969: To the phylogeny of genera of the family Myobiidae (Acarina). Acarologia 11: 537-574.

DUSBÁBEK F. 1973: A systematic review of the genus Pteracarus (Acariformes: Myobiidae). Acarologia 15: 240-288.

FAIN A. 1973: Notes sur la nomenclature des poils idiosomaux chez les Myobiidae avec description de taxa nouveaux. Acarologia 15: 289-309.

FAIN A. 1994: Adaptation, specificity and host-parasite coevolution in mites (Acari). Int. J. Parasitol. 24: 12731278.

FAIN A., BOCHKOV A.V. 2002: On some little known and a new species of Myobiidae (Acari) associated with rodents. Bull. Soc. R. Belge Entomol. 138: 95-105.

FAIN A., LUKOSCHUS F.S. 1976: Myobiidae parasites d'Insectivores. Acta Zool. Pathol. Antverp. 66: 121-188.
GRANDJEAN F. 1939: Les segments postlarvaires de l'hystérosoma chez les oribates (Acariens). Bull. Soc. Zool. Fr. 64: 273-284.

GRANDJEAN F. 1944: Observations sur les acariens de la famille des Stigmaeidae. Arch. Sci. Phys. Nat. 26: 103131.

JENKINS P.D., ROBINSON M.F. 2002: Another variation on the gymnure theme: description of a new species of Hylomys (Lipotyphla, Erinaceidae, Galericinae). Bull. Nat. Hist. Mus. Zool. Ser. 68: 1-11.

KETHLEY J.B. 1982: Prostigmata. In: S.P. Parker (Ed.), Synopsis and Classification of Living Organisms. Vol. 2. McCraw-Hill Inc., New York, pp. 117-145.

LUKOSCHUS F.S., DRIESSEN F.M. 1971: Amorphacarus parvisetosus spec. nov. (Myobiidae, Trombidiformes) from Neomys fodiens Pennant (Soricidae). Tijdschr. Entomol. 114: 163-172.

STANHOPE M.J., WADDELL V.G., MADSEN O., DE JONG W.W., HEDGES S.B., CLEVEN G.C., KAO D., SPRINGER M.S. 1998: Molecular evidence for multiple origins of Insectivora and for a new order of African insectivore mammals. Proc. Natl. Acad. Sci. USA 95: 96679672.

UCHIKAWA K. 1986: Chimarrogalobia yoshiyukiae gen. n., sp. n. (Acarina, Myobiidae) parasitic on Chimarrogale (Insectivora, Soricidae). Zool. Sci. 3: 187-192. 